\title{
Influence of deciduous molar hypomineralization on the development of molar-incisor hypomineralizarion
}

\author{
Cristiane Maria Costa-Silva', Janice Simpson de Paula², Glaucia Maria Bovi Ambrosano ${ }^{3}$, Fábio Luiz Mialhe ${ }^{3}$
}

${ }^{1}$ Department of Health, Oral Health Coordination from Poços de Caldas City Hall, Poços de Caldas, MG, Brazil

${ }^{2}$ Federal Institute of Education, Science and Technology of Southeast Minas Gerais (IFET), Barbacena, MG, Brazil

${ }^{3}$ Department of Community Dentistry, Piracicaba Dental School, UNICAMP - University of Campinas, Piracicaba, SP, Brazil

\begin{abstract}
Defects similar to Molar-Incisor Hypomineralization (MIH) in second primary molars can be found in the literature, being recently named Deciduous Molar Hypomineralization (DMH). Researchers have stated that the presence of DMH in primary dentition represents a risk for MIH in permanent teeth. The explanation for this association is probably related to the etiological factors. Aim: To investigate prospectively the association between $\mathrm{DMH}$ and $\mathrm{MIH}$ and the etiologic factors involved in both defects. Methods: One hundred and thirty four children aged 4 to 6 years from Botelhos, MG, Brazil, were evaluated six-monthly until they completed the eruption of the first permanent molars. A structured questionnaire was developed with questions about the child's health up to the first year of life and the mother's health during pregnancy. Results: It could be noted that, although most children with DMH in the primary dentition had higher incidence of MIH in permanent dentition, this difference was not statistically significant. Conclusions: None of the possible etiologic factors had associations with the studied enamel defects, even among children who presented two types of enamel defects in the mixed dentition. However, further studies with larger samples should be conducted in order to confirm or refute the findings of the present study.
\end{abstract}

Keywords: oral health, etiology, tooth demineralization, dental caries.

\section{Introduction}

In 2001, the term Molar-Incisor Hypomineralization (MIH) was proposed by Weerheijm et al. ${ }^{1}$ (2001) to describe localized enamel defects in permanent molars and incisors. Although the etiology of MIH remains poorly understood ${ }^{2}$, it suggests

Received for publication: September 21, 2013

Accepted: December 03, 2013

\section{Correspondence to:} Fábio Luiz Mialhe Departamento de Odontologia Social Faculdade de Odontologia de Piracicaba Universidade Estadual de Campinas Avenida Limeira 901, CEP: 13414-903 Bairro Areão, Piracicaba, SP, Brasil Phone: +55 1921065279

Fax: +55 1934210144 E-mail: mialhe@fop.unicamp.br that their cause has systemic origin ${ }^{1,3,4}$. Several factors have been suggested as associated with the development of the defect, such as pre-and perinatal problems, diseases and frequent use of antibiotics during early childhood, among other causes ${ }^{5-9}$.

Reports of defects similar to MIH in second molars can be found in the literature $^{10,11}$, which was recently named Deciduous Molars Hypomineralization $(\mathrm{DMH})$. In addition to their asymmetric distribution, other similar features between $\mathrm{DMH}$ and MIH draw attention, as post-eruptive structural losses and atypical restorations ${ }^{11}$.

Researchers suggest that the presence of DMH in primary dentition presents a risk to the permanent presence of $\mathrm{MIH}^{12}$. The explanation for this association is probably related to the etiological factors of developmental defects in enamel, because 
these factors are also related to the development of MIH defects of enamel in the primary dentition ${ }^{13-16}$. Injuries that occur in late pregnancy and in early perinatal period could affect both dentitions, resulting in similar enamel defects, depending on its intensity and duration ${ }^{8,14,17}$.

However, despite being reported that children with $\mathrm{DMH}$ have higher chances of MIH in the permanent dentition ${ }^{12,18}$ these statements were based on studies in which assessments of teeth were performed at a stage where there was an overlap between the presence of the first permanent molars and second molars. Therefore, up to now, there are no prospective studies involving with young children presenting second deciduous molars and carefully accompanied until the eruption of the first permanent molars. Nor are there in the literature studies investigating the association between etiological factors involved in both defects. These issues represent the objectives of this study.

\section{Material and methods}

\section{Ethical Aspects}

Approval for this assessment was obtained from the Ethics Committee of the Piracicaba Dental School, São Paulo, Brazil (Protocol 037/2010). Parents of the participants in the study gave their informed consent before the study began.

\section{Subjects}

Children from all public schools born between January, 2004 and December, 2006, who lived in urban and rural areas of Botelhos, MG, Brazil were invited to participate. The city has slightly over 15,000 inhabitants and has a Human Development Index of 0.7. The level of fluoride in the community water after fluoridation is $0.7 \mathrm{ppm} / \mathrm{F}$.

Children were excluded if they were absent on the day of the examination or if their parents declined to give their consent. A total of 134 children participated in the study.

\section{Assessment of clinical factors}

The first exam was carried out in school environment by the first author (CMCS) in May, 2010, according to the World Health Organisation guidelines for epidemiologic oral health studies. First, the researcher was calibrated and intraexaminer consistency was calculated by re-examinations of 5.5\% of participants in the sample, using the Kappa statistics.

The clinical epidemiological investigations were conducted under natural light with the aid of mirrors and ballpoint probes (used only for removal of debris and food remains that could difficult the observation of tooth surfaces), according to the WHO criteria for epidemiological surveys. In order to observe the presence of DHM and subsequently the MIH, the surfaces of the teeth were examined without drying after monitored brushing. Only children who were in the deciduous dentition phase were included in the survey.

All second primary molars were examined for demarcated enamel opacity, according to European Academy of Paediatric Dentistry (EAPD) criteria for the diagnosis of MIH in permanent dentition ${ }^{10}$. Any participant who presented demarcated enamel opacity on at least one surface of any second primary molar was diagnosed with DMH. Defects of smaller than $1 \mathrm{~mm}$ were not reported in this study ${ }^{11}$.

The children were prospectively evaluated for two years, by six-monthly evaluation until they completed the eruption of the first permanent molars. The presence of these MIH teeth was evaluated according to the same criteria used for analysis of deciduous teeth.

\section{Assessment of etiological factors}

The possible factors involved in the etiology of hypomineralized enamel defects were reviewed in the literature to produce a specific questionnaire for this study and for the parents. This questionnaire contained only structured questions and was pre-tested on a sub-population of Botelhos. This questionnaire guided the evaluation of pre-and peri-natal factors, as well as data on the child's health until the first year of life, the time at which there is coincidence between the mineralization of the crowns of the second molars and formation of crowns of the first permanent molars ${ }^{19}$. To avoid the bias of memory, parents were advised to check the health card of mother and child to answer the questionnaire.

\section{Statistical analysis}

The Fisher's exact test, with significance level of 5\% to evaluate associations between the presence of DMH and MIH was used. In addition, the sample was categorized according to the absence or presence of DMH and MIH, which correspond to the dependent variable. Then, 4 groups were formed: children with $\mathrm{DMH}$ and $\mathrm{MIH}$, children with $\mathrm{MIH}$ and without $\mathrm{DMH}$, children with $\mathrm{DMH}$ and without $\mathrm{MIH}$, children with MIH and no DMH. The dependent variables (gender, age, rural or urban residence, treated water, illness of mother during pregnancy, type of delivery) were statistical data associated with dependent variables using the Fisher's exact test, with a significance level of 5\%. The statistical tests were performed using the SAS software.

\section{Results}

In this sample, $20.14 \%(n=27)$ of the children had at least one second primary molar with DMH at baseline. The severity of DMH was considered mild in all cases, since there was no structural loss defects related to enamel. After two years of monitoring performed every six months until all four first permanent molars erupted in the oral cavity, $15.67 \%(n=21)$ showed MIH in at least one of these teeth.

In the final examination, $5.22 \%(n=7)$ of all evaluated children showed simultaneously DMH and MIH. Table 1

Table 1. Relationship between the DMH in the primary dentition and the incidence of MIH in the mixed dentition.

\begin{tabular}{llcccc}
\hline MIH & \multicolumn{2}{c}{ DMH present } & \multicolumn{1}{c}{ DMH absent } & $\mathbf{p}^{*}$ \\
& $\mathrm{~N}$ & $\%$ & $\mathrm{~N}$ & $\%$ & \\
\cline { 2 - 6 } Present & 7 & 30.43478 & 16 & 69.56522 & 0.250 \\
Absent & 20 & 18.01802 & 91 & 81.98198 & \\
\hline
\end{tabular}

${ }^{*}$ Fischer's exact test 
Table 2. Etiological factors related to demarcated enamel opacities in children.

\begin{tabular}{|c|c|c|c|c|c|c|}
\hline & $\begin{array}{l}\text { With MIH } \\
\text { and DMH }\end{array}$ & $\begin{array}{c}\text { Without MIH } \\
\text { and DMH }\end{array}$ & $\begin{array}{l}\text { Without MIH } \\
\text { and with DMH }\end{array}$ & $\begin{array}{c}\text { Without MIH } \\
\text { and DMH }\end{array}$ & Total & p \\
\hline \multicolumn{7}{|l|}{ Gender } \\
\hline Female & 6 & 9 & 7 & 48 & 70 & 0.1354 \\
\hline Male & 1 & 7 & 13 & 43 & 64 & \\
\hline \multicolumn{7}{|l|}{$\overline{\text { Age }}$} \\
\hline$<5$ years & 4 & 10 & 12 & 37 & 63 & 0.1940 \\
\hline$>5$ years & 3 & 6 & 8 & 54 & 71 & \\
\hline \multicolumn{7}{|l|}{ Residence } \\
\hline Rural & 5 & 12 & 18 & 73 & 108 & 0.6774 \\
\hline Urban & 2 & 3 & 2 & 18 & 25 & \\
\hline \multicolumn{7}{|l|}{ Access to water } \\
\hline Public water treated & 5 & 11 & 18 & 72 & 106 & 0.3547 \\
\hline From mine & 2 & 3 & 1 & 17 & 23 & \\
\hline \multicolumn{7}{|c|}{ Diseases during pregnancy. } \\
\hline No & 4 & 11 & 15 & 70 & 100 & 0.6480 \\
\hline Yes & 3 & 2 & 4 & 21 & 30 & \\
\hline \multicolumn{7}{|l|}{ Type of delivery } \\
\hline Cesarean & 5 & 9 & 11 & 62 & 87 & 0.8398 \\
\hline Vaginal & 2 & 5 & 8 & 29 & 44 & \\
\hline \multicolumn{7}{|l|}{ Weight at birth } \\
\hline Normal & 6 & 11 & 14 & 80 & 111 & 0.6704 \\
\hline Low weight & 1 & 3 & 2 & 11 & 17 & \\
\hline \multicolumn{7}{|l|}{ Preterm birth } \\
\hline Yes & 5 & 6 & 11 & 56 & 78 & 0.1866 \\
\hline No & 0 & 4 & 1 & 23 & 28 & \\
\hline \multicolumn{7}{|l|}{ Breathing problems } \\
\hline No & 5 & 10 & 15 & 61 & 91 & 0.6166 \\
\hline Yes & 2 & 3 & 3 & 29 & 37 & \\
\hline
\end{tabular}

* Fisher's exact test

presents the results of statistical analysis regarding the associations found between the prevalence of DMH in the primary dentition and the incidence of MIH in permanent dentition. It may be observed that although most children with DMH in the primary dentition had higher incidence of MIH in permanent dentition, this difference was not statistically significant between the groups of children with and without DMH $(\mathrm{p}=0.250)$.

Regarding the possible factors involved in the etiology of DMH and MIH during follow-up, it was observed that none of the variables related to the child, its context and birth problems in pregnancy had associations with the studied enamel defects, even among those who presented two types of enamel defects in the mixed dentition (Table 2).

\section{Discussion}

The prevalence of DMH and MIH found in this study was higher compared to other studies in Europe ${ }^{11,12,18}$. However, in 2011, a population-based survey, conducted on the same population of this study demonstrated a high prevalence of MIH among evaluated children ${ }^{20}$, which highlights a possible influence of environmental factors as originating these defects ${ }^{21}$. Another possibility for the discrepancy of the obtained values may relate to differences in sample size and lifestyles among people of a developing country, when compared with the populations of more developed countries. This is, to the best of our knowledge, the first longitudinal study evaluating variables associated with the etiology of DMH. Although the several studies on this topic, the etiology of MIH remains unclear until now ${ }^{13,21}$. Several factors are mentioned in the literature, like prematurity, illness and antibiotic use during infancy, exposure to dioxin, high fever and hypocalcemia ${ }^{3,8,22,23}$. Thus, the results of this study are similar to those found in literature, and it was not possible to find among the studied factors, which of them could be involved in the etiology of MIH and $\mathrm{DMH}$.

Researchers suggest that DMH can serve as an alert for possible MIH in the permanent dentition ${ }^{12,18}$. Again, the hypothesis for this relationship would be related to the coincidence of the period of formation between the affected two groups of teeth, as well as the same etiologic factors. This is also, to the best of our knowledge, the first study to prospectively evaluate the relationship between the DMH in the primary dentition and MIH in permanent. However, no coincidence was observed between both defects. This fact does not allow us to confirm the results of other studies that showed in cross-sectional assessments the coincidence of the presence of DMH in the primary dentition and $\mathrm{MIH}$ in 
permanent dentition. Although children with DMH presented higher incidence of $\mathrm{MIH}$ in the permanent dentition in present study, this difference was not statistically significant. However, some limitations of this study, as the sample size, a factor that may have affected the statistical results, point out to further studies with larger samples to be conducted in order to confirm or refute the findings of the present study. Regardless of the findings of this study, it is important that dental professionals draw attention to the post-eruptive structural losses of DMH and $\mathrm{MIH}$, which should be adequately restored and followed over time to prevent future extractions and reduction in the children's quality of life ${ }^{11,24-26}$.

In conclusion, no associations were found between the studied etiological factors and the development of MIH and $\mathrm{DMH}$ in the longitudinal follow-up of 2 years. Furthermore, there was no significant association between the presence of $\mathrm{DMH}$ in the primary dentition and permanent in MIH. This fact highlights the need for developing further studies in diverse and larger populations to confirm or refute the obtained results.

\section{References}

1. Weerheijm KL, Jälevik B, Alaluusua, S. Molar incisor hypomineralization. Caries Res. 2001; 35: 390-1.

2. Alaluusua S. Aetiology of Molar-Incisor Hypomineralization: A systematic review. Eur J Paediatr Dent. 2010; 11: 53-8.

3. Beentjes VEVM, Weerheijm KL, Groen HJ. Factors involved in the aetiology of molar-incisor hypomineralization. Eur J Paediatr Dent. 2002; 1: 9-13.

4. Combrie F, Manton D, Kilpatrick N. Aetiology of molar-incisor hypomineralization: a critical review. Int J Paediatr Dent. 2009; 19: 73-83.

5. Jälevik B, Norén JG, Klingberg G, Barregard L. Etiologic factors influencing the prevalence of demarcated opacities in permanent first molars in a group of Swedish children. Eur J Sci. 2001; 109: 230-4.

6. Preusser SE, Ferring V, Wleklinski C, Wetzel WE. Prevalence and severity of molar incisor hypomineralization in a region of Germany - a brief communication. J Public Health Dent. 2007; 67: 148-50.

7. Kuscu OO, Caglar E, Sandalli N. The prevalence and etiology of Molar Incisor Hypomineralization in a group of children in Istanbul. Eur J Paediatr Dent. 2008; 9: 139-44.

8. Whatling R, Fearne JM. Molar incisor hypomineralization: a study of etiological factors in a group of UK children. Int J Paediatr Dent. 2008; 18 : $155-62$.

9. Laisi S, Ess A, Sahlberg C, Arvio P, Lukinma PL, Alaluusua S. Amoxicillin may cause Molar Incisor Hypomineralization. J Dent Res. 2009; 88: 132-6.

10. Weerheijm KL, Duggal M, Mejàre I, Papagiannoulis L, Koch G, Martens $\mathrm{LC}$, et al. Judgement criteria for molar incisor hypomineralization $(\mathrm{MIH})$ in epidemiologic studies: a summary of the European meeting on $\mathrm{MlH}$ held in Athens, 2003. Eur J Paediatr Dent. 2003; 4: 110-3.

11. Elfrink MEC, Schuller AA, Weerheijm KL, Veerkamp JSJ. Hypomineralised second primary molars: prevalence data in dutch 5year-olds. Caries Res. 2008; 42: 282-5.

12. Elfrink MEC, ten Cate JM, Jaddoe VWV. Hofman A, Moll HA, Veerkamp JSJ. Deciduous Molar Hypomineralization and Molar Incisor Hypomineralization. J Dent Res. 2012; 91: 551-5.

13. Combrie F, Manton D, Kilpatrick N. Aetiology of molar incisor hypomineralization: a critical review. Int J Paediatr Dent. 2009; 19: 73-83.

14. Li Y, Navia JM, Bian JY. Prevalence and distribution of developmental enamel defects in primary dentition of Chinese children 3-5 years old. Community Dent Oral Epidemiol. 1995; 23: 72-9.
15. Seow WK. Clinical diagnosis of enamel defects: pitfalls and practical guidelines. Int Dent J. 1997; 47: 173-82.

16. Staylon RL, Warren JJ, Kanellis MJ, Levy SM, Islam M. Prevalence of enamel hypoplasia and isolated opacities in primary dentition. Pediatr Dent 2001; 23: 32-6.

17. Van Amerongen WE, Kreulen CM. Cheese molars: a pilot study of the etiology of hypocalcifications in first permanent molars. ASDC J Dent Child. 1995; 62: 266-9.

18. Ghanim A, Manton D, Mariño R, Morgan M, Bailey D. Prevalence of demarcated hypomineralisation defects in second primary molars in Iraqi children. Int J Paediatr Dent. 2012; 25: 1-8.

19. Moorres CFA, Gron AM, Lebert LM, Yen PK, Frolich FJ. Growth studies of the dentition - a review. Am J Orthod. 1969; 55: 600-16.

20. Costa-Silva CM, Ambrosano GMB, Jeremias F, Souza JF, Mialhe FL. Increase in severity of molar-incisor hypomineralization and its relationship with the colour of enamel opacity: a prospective cohort study. Int J Paediatr Dent. 2011; 21: 333-41.

21. Souza JF, Costa-Silva CM, Jeremias F, Santos-Pinto L, Zuanon AC, Cordeiro RC. Molar incisor hypomineralisation: possible aetiological factors in children from urban and rural areas. Eur Arch Paediatr Dent. 2012; 13 : 164-70.

22. Alaluusua S, Kukinmaa PL, Vartiainen T, Partanen M, Torppa J, Tuomisto J. Polydibenzofurans via mother's milk may cause developmental defects in the child's teeth. Environ Toxicol Pharmacol. 1996; 1: 193-7.

23. Jälevik B, Norén JG. Enamel hypomineralization of permanent first molars: a morphological study and survey of possible aetiological factors. Int J Paediatr Dent. 2000; 10: 278-89.

24. Fonseca RB, Correr Sobrinho L, Fernandes Neto AJ, Mota AS, Soares CJ. Enamel hypoplasia or amelogenesis imperfecta: a restorative approach. Braz J Oral Sci. 2006; 5: 941-3.

25. Xavier A, Carvalho FS, Bastos RSB, Caldana ML, Bastos JRM. Dental caries-related quality of life and socioeconomic status of preschool children, Bauru, SP. Braz J Oral Sci. 2012; 11: 463-8.

26. Costa-Silva CM, Mialhe FL. Considerations for clinical management of molar-incisor hypomineralization: A literature review. Rev Odonto Cienc. 2012; 27: 333-8. 